\title{
Characterizing immune evasion in FFPE tissue sections - a new method for measuring cellular interactions via multiplexed phenotype mapping and spatial point patterns
}

\author{
Clifford Hoyt ${ }^{1 *}$, Chichung Wang ${ }^{1}$, Kristin Roman ${ }^{1}$, Kent Johnson ${ }^{1}$, Peter Miller ${ }^{1}$, Elizabeth Mittendorf ${ }^{2}$ \\ From Society for Immunotherapy of Cancer 29th Annual Meeting \\ National Harbor, MD, USA. 6-9 November 2014
}

\section{Background}

Full realization of the potential of immunotherapy will require biomarkers that capture immuno-tumor interactions. This will most effectively be achieved by phenotyping cells in-situ in intact tissue sections. Such methods will potentially predict response to drugs and monitor efficacy and onset of resistance. Existing methods are limited. Here we report a novel integrated approach, utilizing highly multiplexed immunofluorescence labeling, imaging-based analysis to capture expression and cellular interactions in tumor and the microenvironment, and statistical analysis. Of particular interest is applicability of this approach to intact FFPE tissue sections, amenable to routine pathology workflow. The capability of this technology to show the range of immune-tumor interactions is demonstrated on a set of breast cancer samples.

\section{Methods}

Breast specimens were labeled for CD4, CD8, CD20, PDL1, Foxp3, cytokeratin, and DAPI with a new serial samespecies fluorescence labeling approach utilizing tyramide signal amplification $\left(\mathrm{Opal}^{\mathrm{TM}}\right)$, and microwave-based antigen retrieval and antibody stripping, which enables specific, non-interfering, balanced labeling. Samples were imaged on a multispectral slide analysis system, and analyzed with pattern recognition software, to segment tissue into tumor and stroma, and phenotype cells using a new multinomial logistic regression learning capability that is intuitive, fast, and reliable across clinical variability. Cells

${ }^{1}$ Perkin Elmer, Inc., USA

Full list of author information is available at the end of the article were phenotyped into categories of tumor, killer $\mathrm{T}$, helper $\mathrm{T}$, regulatory $\mathrm{T}, \mathrm{B}$ cells, producing cell phenotype maps retaining spatial arrangements. Imagery was assessed by a pathologist for segmentation and cell phenotyping accuracy, and then evaluated using spatial point pattern analysis. As an example statistic, nearest-neighbor calculations are performed to determine percentage of tumor cells having killer $\mathrm{T}$ cells within 25 microns.

\section{Results}

Labeling of five breast cancer samples demonstrated specificity and sensitivity estimated by a pathologist to be greater than $95 \%$ accurate. The five cases presented significantly different killer $\mathrm{T}$ and tumor cell interaction statistics. As an example, nearest-neighbor analysis indicates the five cases had, respectively, $54 \%, 10 \%, 61 \%, 33 \%$, and $55 \%$ of tumor cells having killer $\mathrm{T}$ cells within 25 microns (Example case in Figure 1). This is one metric of many that will be presented, that clearly delineate immune-tumor interactions.

\section{Conclusions}

The approach shows reliable detection of immune cell phenotypes and segmentation of tumor and stroma, to accurately assess interaction between immune and tumor cells. We believe results support the feasibility of a practical and viable clinical workflow, in which immune response assessment is automated by computer and results are reviewed by pathologists to assure data quality.

\section{Authors' details}

'Perkin Elmer, Inc., USA. ${ }^{2}$ MD Anderson Cancer Center, University of Texas, Houston, TX, USA. 
- Convenient online submission

- Thorough peer review

- No space constraints or color figure charges

- Immediate publication on acceptance

- Inclusion in PubMed, CAS, Scopus and Google Scholar

- Research which is freely available for redistribution 